\title{
Are Serum Interleukin 6 and Surfactant Protein D Levels Associated with the Clinical Course of COVID-19?
}

\author{
Buğra Kerget $^{1}$ (D) $\cdot$ Ferhan Kerget ${ }^{2} \cdot$ Abdullah Osman Koçak $^{3} \cdot$ Ahmet Kızıltunç $^{4} \cdot$ Ömer Araz $^{1}$ - Elif Yılmazel Uçar ${ }^{1}$. \\ Metin Akgün ${ }^{1}$
}

Received: 26 June 2020 / Accepted: 7 September 2020 / Published online: 12 September 2020

(c) Springer Science+Business Media, LLC, part of Springer Nature 2020

\begin{abstract}
Purpose SARS-CoV-2 (COVID-19) has infected more than 7 million people worldwide in the short time since it emerged in Wuhan, China in December 2019. The aim of this study was to investigate the relationship between serum interleukin 6 (IL-6) and surfactant protein D (SP-D) levels and the clinical course and prognosis of COVID-19.

Materials and Methods The study included a total of 108 individuals: 88 patients who were diagnosed with COVID-19 by real-time PCR of nasopharyngeal swab samples and admitted to the Atatürk University Pulmonary Diseases and the Erzurum City Hospital Infectious Diseases department between March 24 and April 15, and 20 asymptomatic healthcare workers who had negative real-time PCR results during routine COVID-19 screening in our hospital.

Results Patients who developed macrophage activation syndrome had significantly higher IL-6 and SP-D levels at the time of admission and on day 5 of treatment compared to the other patients (IL-6: $p=0.001$ for both; SP-D: $p=0.02, p=0.04$ ). Patients who developed acute respiratory distress syndrome had significantly higher IL-6 and SP-D levels at both time points compared to those who did not $(p=0.001$ for all). Both parameters at the time of admission were also significantly higher among nonsurvivors compared to survivors (IL-6: $p=0.001$, SP-D: $p=0.03$ ).

Conclusion In addition to IL-6, which has an important role in predicting course and planning treatment in COVID-19, SP-D may be a novel pneumoprotein that can be used in the clinical course, follow-up, and possibly in future treatments.
\end{abstract}

Keywords COVID-19 $\cdot$ Interleukin $6 \cdot$ Surfactant protein D $\cdot$ Acute respiratory distress

Electronic supplementary material The online version of this article (https://doi.org/10.1007/s00408-020-00393-8) contains supplementary material, which is available to authorized users.

Buğra Kerget

bjkerget1903@gmail.com

1 Department of Pulmonary Diseases, Ataturk University School of Medicine, 25240 Erzurum, Yakutiye, Turkey

2 Depertmant of Infection Diseases and Clinical Microbiology, Health Sciences University Erzurum Regional Education and Research Hospital, Erzurum, Turkey

3 Department of Emergency Medicine, Ataturk University School of Medicine, 25240 Erzurum, Yakutiye, Turkey

4 Department of Biochemistry, Ataturk University School of Medicine, 25240 Erzurum, Turkey

\section{Introduction}

Coronavirus disease 2019 (COVID-19) emerged in Wuhan, China in December 2019 and rapidly spread across the globe. In June 2020, the number of confirmed cases passed 7 million and continues to increase. Most infected patients are asymptomatic or have mild symptoms such as sore throat, loss of taste and smell, malaise, and joint pain. However, older adults ( $>50$ years old), people with certain comorbidities (diabetes, hypertension), and those with impaired immunity (HIV infection, immunosuppressive therapy, pregnancy) are susceptible to more severe manifestations of COVID-19 [1].

The most common of these are acute respiratory distress syndrome (ARDS) with hypoxemic respiratory failure and macrophage activation syndrome (MAS). In both of these clinical conditions, overexpressed proinflammatory cytokines lead to endothelial dysfunction and can cause damage to vital organs, primarily the lungs. The most 
frequently used parameters with prognostic significance in COVID-19 include D-dimer, interleukin 6 (IL-6), fibrinogen, and ferritin levels, leukopenia, and prothrombin time [2-4].

Surfactant protein D (SP-D), which is a member of the innate immune system, is one of the collectin family of proteins synthesized by Type 2 alveolar epithelium. In addition to SP-D, other members of this family include SP-A and mannose-binding lectin (MBL). These proteins mainly target alveolar macrophages, dendritic cells, and $\mathrm{T}$ cells and play an important role in agglutination, opsonization, and modulation. Studies have shown that SP-D levels increase with disease severity and IgG level in patients infected with SARS-CoV, a similar coronavirus responsible for severe acute respiratory syndrome (SARS) [5, 6].

The aim of the present study was to evaluate the relationship between IL-6 level, an established prognostic marker in COVID-19, and SP-D level, which is closely associated with the clinical course of SARS, and clinical course and prognosis in COVID-19 patients.

\section{Materials and Methods}

The study included patients who presented to emergency department of Atatürk University and the Erzurum City Hospital with symptoms such as recent-onset fever, cough, shortness of breath, fatigue, and sudden attenuation of taste and smell and had returned from travel abroad or had contact with a suspected COVID-19 patient within the past 14 days.

For patients with risk factors for COVID-19, posterioranterior chest X-rays were obtained and if suspicious lesions were detected, a more detailed examination was performed using high-resolution thoracic computed tomography. COVID-19 diagnosis was made based on real-time reverse transcriptase (RT)-PCR diagnostic testing of nasopharyngeal swab samples obtained from the patients. The first SARSCoV-2-positive patients presented to Erzurum City Hospital and Atatürk University on March 20 and 24, respectively. This study included 88 COVID-19 patients treated in the pulmonology and infectious diseases departments of these centers between March 24 and April 15 and a control group of 20 asymptomatic healthcare workers who had negative RT-PCR results during routine COVID-19 screening in our hospital and volunteered to participate. The patients' hematological parameters, biochemical parameters including liver and kidney function tests, coagulation parameters, ferritin, D-dimer, troponin-I, CRP, and arterial blood gas parameters were evaluated at admission and daily thereafter.

\section{Definitions and Diagnosis}

Axillary temperature over $37.3{ }^{\circ} \mathrm{C}$ was regarded as fever. Presence of signs and symptoms of bacteremia or pneumonia together with an endotracheal aspirate or lower respiratory tract sputum culture positive for a new pathogen was evaluated as secondary bacterial infection. Patients diagnosed as having ventilator-associated or hospital-acquired pneumonia were treated according to the available guidelines. ARDS was diagnosed and classified using the 2015 Berlin diagnostic criteria. If the daily cardiac-specific troponin-I level of the patients was above normal, the patient was evaluated by echocardiography for newly developed cardiac pathologies. Coagulopathy was defined as prothrombin and partial thromboplastin times prolonged by $3 \mathrm{~s}$ and $5 \mathrm{~s}$, respectively. Based on disease severity, treatment was planned according to the COVID-19 adult diagnosis and treatment guidelines published by the Turkish Ministry of Health. Patients exhibiting findings such as persistent fever, C-reactive protein (CRP), and ferritin levels that remain high or continue to increase, D-dimer elevation, thrombocytopenia or lymphopenia, abnormal liver function tests, hypofibrinogenemia, or elevated triglyceride levels despite treatment were followed up for MAS. If repeated measures of these parameters showed continued deterioration that could not be explained by secondary bacterial infection, the patients were given $400 \mathrm{mg}$ tocilizumab for MAS if not contraindicated. Clinical and laboratory response was evaluated after $24 \mathrm{~h}$. Only patients who did not respond were given another $400 \mathrm{mg}$ of tocilizumab.

\section{Measurement of Biochemical Markers}

Peripheral venous blood samples were collected after $15 \mathrm{~min}$ of rest into tubes containing ethylenediaminetetraacetic acid (EDTA). Troponin-I levels were measured by chemiluminescent immunoassay using an Immulite 2500 device (Siemens Medical Solutions, Erlangen, Germany). IL-6 and SP-D levels were measured by enzyme-linked immunosorbent assay (Elabscience human ELISA kit, UK).

\section{Statistical Analysis}

The data were analyzed using IBM SPSS Statistics for Windows version 20.0 (IBM Corp., Armonk, NY). Pearson's chi-square test and Mann-Whitney $\mathrm{U}$ test were used for intergroup comparisons of parametric data and nonnormally distributed numerical data, respectively. Independent samples $t$-test was used to compare demographic data and laboratory parameters between the groups. Wilcoxon analysis 
was used for intragroup comparisons of laboratory values during follow-up. Spearman correlation analysis was used to evaluate relationships between IL-6 and SP-D levels, while Pearson correlation analysis was used to evaluate correlations of IL-6 and SP-D with CRP, ferritin, D-dimer, lymphocyte, neutrophil/lymphocyte ratio, troponin-I, and $\mathrm{PaO}_{2} /$ $\mathrm{FiO}_{2}$. A $p$-value less than 0.05 was considered statistically significant.

\section{Results}

Of the patients included in our study, 47 (53.4\%) were female and $41(46.6 \%)$ were male. The control group included $12(60 \%)$ females and $8(40 \%)$ males. Mean age was $49.1 \pm 21.1$ years in the patient group and $35.2 \pm 6.9$ years in the control group. No statistically significant difference was detected between the groups in terms of age or sex ( $p=0.196, p=0.34$ ). Comorbidities observed in the COVID19 patients and their relationship with the parameters are shown in supplementary Tables 1,2 . Patients in the control group had no comorbidities or history of smoking.

Comparative analysis of the patients' laboratory parameters at time of admission and on day 5 of follow-up, and the IL-6 and SP-D levels of the control subjects are shown in Table 1 (Figs. 1,2). The patients had significantly higher IL-6 and SP-D levels at admission than on day 5 ( $p=0.001$ for both). The patients' IL-6 and SP-D levels at admission were significantly higher than in the control group $(p=0.001$ for both). At day 5, these values were still higher than in the control group, but the difference was not statistically significant ( $p=0.08, p=0.2$ ). Comparative analysis of the laboratory parameters of patients who developed MAS $(n=20)$ and did not develop MAS $(n=68)$ at the time of admission and on day 5 of follow-up is presented in Tables 2, 3, 4. Compared to patients without MAS, patients with MAS had significantly higher levels of IL-6 and SP-D at admission and on day 5 (IL-6: $p=0.001$ for both; SP-D: $p=0.02, p=0.04$ ). Comparative analysis of the laboratory parameters at admission and on day 5 of follow-up in patients who developed $\operatorname{ARDS}(n=35)$ and did not develop ARDS $(n=53)$ is shown in Tables 4, 5. Patients who developed ARDS had significantly higher IL-6 and SP-D levels at both time points compared to those who did not ( $p=0.001$ for all). Seven patients died. Comparison of survivors and nonsurvivors showed that the nonsurvivors had significantly higher levels of IL-6 $(150.8 \pm 68.6 \mathrm{pg} / \mathrm{ml}$ vs $46.1 \pm 46.9 \mathrm{pg} / \mathrm{ml}, p=0.001)$ and SP-D $(96.7 \pm 37.2 \mathrm{ng} / \mathrm{ml}$ vs $56.9 \pm 43.5 \mathrm{ng} / \mathrm{ml}, p=0.03)$.

Correlation analysis between IL-6 level and other laboratory parameters at time of admission revealed negative correlations with lymphocyte level $(r=-0.404, p=0.01)$ and $\mathrm{PaO}_{2} / \mathrm{FiO}_{2}(r=-0.636, p=0.01)$ and positive correlations with neutrophil-lymphocyte ratio $(r=0.386, p=0.01)$, lactate dehydrogenase $(r=0.415, p=0.01)$, creatine $(r=0.339, p=0.01)$, prothrombin time $(r=0.57, p=0.01)$, CRP $(r=0.257, p=0.05)$, troponin-I $(r=0.636, p=0.01)$, D-dimer $(r=0.426, p=0.01)$, and SP-D $(r=0.218, p=0.05)$ (Supplementary Figs. 1 and 2). A strong positive correlation
Table 1 Comparison of laboratory parameters of COVID-19 patients at admission and on day 5 of treatment

\begin{tabular}{lccc}
\hline & $\begin{array}{c}\text { Admission }(n=88) \\
(\text { Mean } \pm \mathrm{SD})\end{array}$ & Day 5 of treatment $(n=88)$ & $p$ \\
\hline WBC $(/ \mu \mathrm{L})$ & $7239.7 \pm 4023.8$ & $7158.7 \pm 3370.7$ & 0.82 \\
Lymphocytes $(/ \mu \mathrm{L})$ & $1573.2 \pm 888.4$ & $1823.2 \pm 906.8$ & 0.003 \\
Neutrophils $(/ \mu \mathrm{L})$ & $4987.3 \pm 3614.9$ & $4685.1 \pm 3250.1$ & 0.206 \\
NLR & $5.3 \pm 8.4$ & $4.3 \pm 8.4$ & 0.03 \\
AST $(\mathrm{U} / \mathrm{L})$ & $32.9 \pm 20.5$ & $31.9 \pm 34.1$ & 0.189 \\
ALT $(\mathrm{U} / \mathrm{L})$ & $30.6 \pm 25.2$ & $31.3 \pm 23.4$ & 0.225 \\
LDH $(\mathrm{U} / \mathrm{L})$ & $311.7 \pm 159.1$ & $305.1 \pm 199.9$ & 0.275 \\
GGT $(\mathrm{U} / \mathrm{L})$ & $39.9 \pm 34.2$ & $40.6 \pm 35.7$ & 0.317 \\
ALP $(\mathrm{U} / \mathrm{L})$ & $79.1 \pm 41.2$ & $69.2 \pm 27.5$ & 0.003 \\
Sodium $(\mathrm{mmol} / \mathrm{L})$ & $138.8 \pm 3.9$ & $140.7 \pm 4.6$ & 0.007 \\
Potassium $(\mathrm{mmol} / \mathrm{L})$ & $4.2 \pm 0.5$ & $4.4 \pm 0.5$ & 0.001 \\
Creatine $(\mathrm{mg} / \mathrm{dL})$ & $1.1 \pm 0.9$ & $1.1 \pm 0.9$ & 0.319 \\
Prothrombin time $(\mathrm{s})$ & $15.9 \pm 6.8$ & $14.6 \pm 5.1$ & 0.001 \\
CRP $(\mathrm{mg} / \mathrm{dL})$ & $63.3 \pm 83.5$ & $27.5 \pm 27.4$ & 0.001 \\
Troponin-I (ng/dL) & $67.1 \pm 297.8$ & $149.7 \pm 1185.2$ & 0.001 \\
PaO $/$ FiO 2 & $294.3 \pm 69.1$ & $323.9 \pm 47.6$ & 0.001 \\
D-Dimer $(\mathrm{ng} / \mathrm{mL})$ & $1151.7 \pm 1809.5$ & $666.7 \pm 925.5$ & 0.001 \\
\hline
\end{tabular}

$W B C$ White blood cells, NLR neutrophil/lymphocyte ratio, AST aspartate aminotransferase, $A L T$ alanine aminotransferase, $L D H$ lactate dehydrogenase, $G G T$ gamma glutamyl transferase, $A L P$ alkaline phosphatase, $I L-6$ interleukin $6, S P$ - $D$ surfactant protein D 


\section{IL-6}

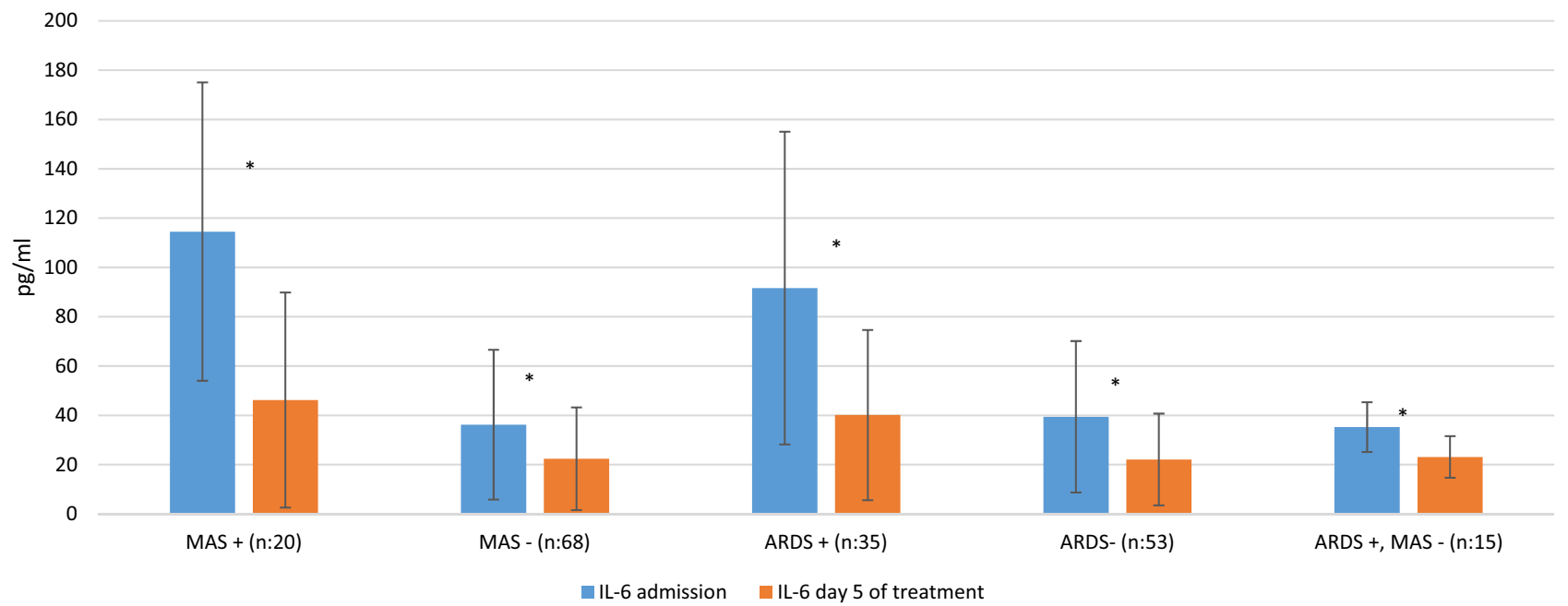

$\mathrm{p}^{*}:$ 0,001 (Comparison of IL-6 levels at time of admission and day 5 of treatment between groups)

Fig. 1 IL-6 levels at admission and on day 5 of treatment in patients with and without MAS and ARDS $p^{*}$ : 0.001 (Comparison of IL-6 levels at time of admission and day 5 of treatment between groups)

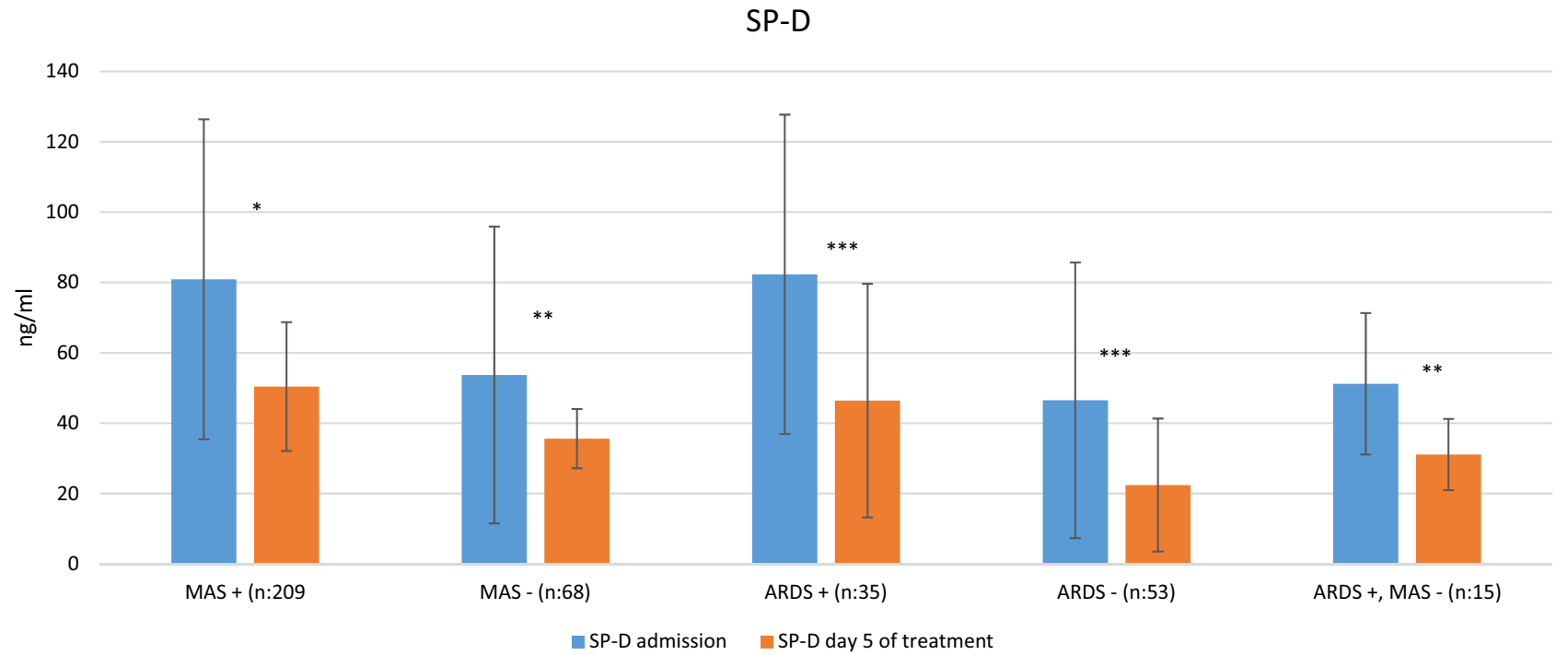

$\mathrm{p}^{*}: 0,02, \mathrm{p}^{* *}: 0,04, \mathrm{p}^{* * *}: 0,001$ (Comparison of SP-D levels at time of admission and day 5 of treatment between groups)

Fig. 2 SP-D levels at admission and on day 5 of treatment in patients with and without MAS and ARDS $p^{*}: 0.02, p^{* *}: 0.04, p^{* * *}: 0.001$ (Comparison of SP-D levels at time of admission and day 5 of treatment between groups)

was detected between IL-6 level and smoking history (packyears) $(r=0.871, p=0.01)$ (Supplementary Fig. 3).

Correlation analysis between SP-D level and other laboratory parameters at time of admission revealed a negative correlation with $\mathrm{PaO}_{2} / \mathrm{FiO}_{2}$ level $(r=-0.364, p=0.01)$ and positive correlations with CRP $(r=0.305, p=0.01)$, troponin-I $(r=0.23, p=0.01)$, ferritin $(r=0.243, p=0.05)$, and D-dimer levels $(r=0.339, p=0.01)$ (Supplementary Fig. 4,5).

\section{Discussion}

In our study, we observed that levels of IL-6 and SP-D were higher in COVID-19 patients compared to the control group and decreased during follow-up. We found that high IL-6 and SP-D levels were strongly associated with ARDS and MAS development. In addition, we observed that IL-6 and SP-D levels were higher in nonsurvivors compared to 
Table 2 Comparison of laboratory parameters at admission and on day 5 among COVID-19 patients who did and did not develop macrophage activation syndrome (MAS)

\begin{tabular}{|c|c|c|c|c|c|}
\hline & \multicolumn{2}{|c|}{ MAS patients $(n=20)$} & \multicolumn{2}{|c|}{ Non-MAS patients $(n=68)$} & \multirow[t]{2}{*}{$p$} \\
\hline & Admission & Day 5 of treatment & Admission & Day 5 of treatment & \\
\hline $\mathrm{WBC}(/ \mu \mathrm{L})$ & $9133.7 \pm 7270.7$ & $8915 \pm 5886.2$ & $6760.1 \pm 2324.1$ & $6705.5 \pm 2191.9$ & $0.17 / 0.01$ \\
\hline Lymphocytes $(/ \mu \mathrm{L})$ & $821.1 \pm 405.9$ & $1028.8 \pm 670.9$ & $1794.7 \pm 872.5$ & $2028.2 \pm 847.9$ & $0.001 / 0.001$ \\
\hline Neutrophils $(/ \mu \mathrm{L})$ & $7513.2 \pm 6404.7$ & $7353.1 \pm 5602.8$ & $4316.3 \pm 1896.9$ & $3996.5 \pm 1807.1$ & $0.04 / 0.001$ \\
\hline NLR & $13.3 \pm 15.1$ & $11.6 \pm 16.6$ & $3.1 \pm 2.6$ & $2.4 \pm 2$ & $0.008 / 0.001$ \\
\hline AST (U/L) & $42.2 \pm 19.7$ & $63.4 \pm 66.2$ & $30.3 \pm 20.3$ & $23.9 \pm 9.7$ & $0.02 / 0.001$ \\
\hline ALT (U/L) & $36.4 \pm 28.3$ & $44.4 \pm 34.5$ & $29.2 \pm 24.5$ & $28 \pm 18.6$ & $0.273 / 0.01$ \\
\hline $\mathrm{LDH}(\mathrm{U} / \mathrm{L})$ & $451.3 \pm 304.3$ & $557.1 \pm 296.1$ & $270.5 \pm 118.5$ & $242 \pm 95.1$ & $0.001 / 0.001$ \\
\hline GGT (U/L) & $57 \pm 47.1$ & $72.3 \pm 54.8$ & $33.3 \pm 23.2$ & $32.6 \pm 23.7$ & $0.04 / 0.001$ \\
\hline $\operatorname{ALP}(\mathrm{U} / \mathrm{L})$ & $81.7 \pm 33.9$ & $66.1 \pm 29.3$ & $77.1 \pm 42.3$ & $70 \pm 37.2$ & $0.66 / 0.61$ \\
\hline Sodium (mmol/L) & $137.5 \pm 6.1$ & $145.2 \pm 7.8$ & $139.1 \pm 3.1$ & $139.6 \pm 2.4$ & $0.3 / 0.001$ \\
\hline Potassium (mmol/L) & $4.2 \pm 0.6$ & $4.5 \pm 0.7$ & $4.2 \pm 0.4$ & $4.4 \pm 0.5$ & $0.8 / 0.49$ \\
\hline Creatine (mg/dL) & $1.8 \pm 1.8$ & $2.1 \pm 1.8$ & $0.9 \pm 0.5$ & $0.8 \pm 0.2$ & 0.04 / 0.001 \\
\hline Prothrombin time (s) & $20.4 \pm 12.4$ & $19.6 \pm 9.3$ & $14.7 \pm 3.5$ & $13.3 \pm 1.8$ & 0.04 / 0.001 \\
\hline $\mathrm{CRP}(\mathrm{mg} / \mathrm{dL})$ & $176.7 \pm 75.7$ & $50.9 \pm 29.8$ & $27.7 \pm 38.7$ & $11.2 \pm 18.4$ & $0.001 / 0.001$ \\
\hline Troponin-I (ng/dL) & $276.1 \pm 607.3$ & $674 \pm 2517.9$ & $8.9 \pm 15.3$ & $3.2 \pm 6$ & $0.001 / 0.02$ \\
\hline $\mathrm{PaO}_{2} / \mathrm{FiO}_{2}$ & $209.8 \pm 67.7$ & $296.3 \pm 42.4$ & $318.9 \pm 47.6$ & $331.7 \pm 46.4$ & $0.001 / 0.004$ \\
\hline D-Dimer (ng/mL) & $2529.9 \pm 3111.7$ & $1327 \pm 1425.5$ & $766.6 \pm 955.2$ & $476.7 \pm 616.6$ & $0.03 / 0.001$ \\
\hline Ferritin $(\mathrm{ng} / \mathrm{mL})$ & $1094.4 \pm 1559.9$ & $490.3 \pm 75.6$ & $346.7 \pm 144.1$ & $134.6 \pm 76.4$ & $0.001 / 0.001$ \\
\hline
\end{tabular}

MAS Macrophage activation syndrome, WBC white blood cells, $N L R$ neutrophil/lymphocyte ratio, AST aspartate aminotransferase, $A L T$ alanine aminotransferase, $L D H$ lactate dehydrogenase, $G G T$ gamma glutamyl transferase, $A L P$ alkaline phosphatase, $C O H b$ Carboxyhemoglobin, $p$ comparison of parameters at time of admission and day 5 of treatment between groups

patients who survived. IL-6, ferritin, CRP, troponin-I, and D-dimer, which are known to be associated with clinical course and are used in the follow-up of COVID-19, were positively correlated with SP-D level and negatively correlated with $\mathrm{PaO}_{2} / \mathrm{FiO}_{2}$.

The International Committee on Taxonomy of Viruses named the novel coronavirus or 2019 "Severe Acute Respiratory Syndrome Coronavirus 2" (SARS-CoV-2) due to its similarity to SARS-CoV. SARS-CoV and MERS-CoV are other coronaviruses that can cause significant morbidity and mortality in humans and have caused epidemics in the past [7]. Laboratory tests demonstrate lymphopenia in most COVID-19 patients [8]. This suggests that like SARSCoV, SARS-CoV-2 may preferentially affect lymphocytes, particularly T lymphocytes. Viral particles spread from the respiratory mucosa to infect other cells, causing a cytokine storm. T lymphocyte damage is believed to be an important factor in the development of this cytokine storm [9]. Therefore, it has been suggested that lymphopenia may be a reference parameter that can be used in the diagnosis of COVID-19 [10]. Cytokine storms are characterized by the overproduction of several proinflammatory cytokines, primarily, TNF-alpha, IL-1, IL-2, IL-6, and nitric oxide. These cytokines increase vascular permeability, resulting in impaired tissue perfusion, endothelial damage, and microthrombus formation [11]. The increase in vascular permeability causes fluid to accumulate in the lung tissue and interstitial area, which in turn leads to acute respiratory failure. Favorable results have been reported on the use of the IL-6 antagonist tocilizumab to prevent the development of these complications [2]. IL-6 levels may be increased in diabetes mellitus, coronary artery disease, chronic airway diseases, and smoking, all of which are important factors of morbidity and mortality in COVID-19 [12-15].

In acute respiratory failure, endothelial damage plays an important role in the development and exacerbation of hypoxemic respiratory failure. Type 2 epithelial damage in the alveoli disrupts surfactant production by these cells and leads to the development of microatelectasic areas [16]. Surfactant facilitates expansion of the alveolar wall and also plays a role in innate immune defense. SP-D is a member of collectin protein family, which are also important players in innate immune defense. This family also includes SP-A and MBL [17]. The primary aim of these proteins is to facilitate microbial clearance by enabling the agglutination, opsonization, and modulation of alveolar macrophages, dendritic cells, and $\mathrm{T}$ lymphocytes to damaged cells. In vitro studies with SP-D showed that it modulates antigen presentation to class II $\mathrm{T}$ cells in a dose-dependent manner and plays a role in the clearance 
Table 3 Comparison of laboratory parameters at admission and on day 5 among COVID-19 patients who did and did not develop acute respiratory distress syndrome (ARDS)

\begin{tabular}{|c|c|c|c|c|c|}
\hline & ARDS patients ( $n$ & & Non-ARDS patier & $=53)$ & $p$ \\
\hline & Admission & Day 5 of treatment & Admission & Day 5 of treatment & \\
\hline $\mathrm{WBC}(/ \mu \mathrm{L})$ & $8109.1 \pm 5749.5$ & $8292.1 \pm 4588.6$ & $6665.5 \pm 2151.8$ & $6487.9 \pm 2169.9$ & $0.1 / 0.02$ \\
\hline Lymphocytes $(/ \mu \mathrm{L})$ & $960 \pm 467.3$ & $1188.6 \pm 674.9$ & $1978.1 \pm 870.3$ & $2198.8 \pm 816.2$ & $0.001 / 0.001$ \\
\hline Neutrophils $(/ \mu \mathrm{L})$ & $6411.4 \pm 5117.7$ & $6466.6 \pm 4424.9$ & $4046.8 \pm 1572.3$ & $3630.6 \pm 1571.8$ & $0.002 / 0.001$ \\
\hline NLR & $9.8 \pm 11.9$ & $8.6 \pm 12.8$ & $2.3 \pm 1.1$ & $1.8 \pm 0.9$ & $0.001 / 0.001$ \\
\hline AST (U/L) & $42.9 \pm 25.1$ & $46.6 \pm 52.2$ & $26.4 \pm 13.4$ & $23.5 \pm 10.4$ & $0.001 / 0.003$ \\
\hline ALT (U/L) & $34.1 \pm 30.6$ & $36.5 \pm 26.9$ & $28.5 \pm 20.9$ & $28.3 \pm 20.8$ & $0.3 / 0.1$ \\
\hline $\mathrm{LDH}(\mathrm{U} / \mathrm{L})$ & $434.4 \pm 180.1$ & $464.1 \pm 255.1$ & $230.7 \pm 65.6$ & $214.6 \pm 60.7$ & $0.001 / 0.001$ \\
\hline GGT (U/L) & $55.2 \pm 44.6$ & $56.1 \pm 45.1$ & $29.9 \pm 20$ & $31.7 \pm 25.6$ & $0.001 / 0.03$ \\
\hline $\operatorname{ALP}(\mathrm{U} / \mathrm{L})$ & $90.1 \pm 55.1$ & $67.6 \pm 27.7$ & $71.8 \pm 26.9$ & $70.1 \pm 27.6$ & $0.07 / 0.7$ \\
\hline Sodium (mmol/L) & $137.3 \pm 4.9$ & $142 \pm 6.9$ & $139.7 \pm 2.8$ & $139.9 \pm 2.3$ & $0.005 / 0.06$ \\
\hline Potassium (mmol/L) & $4.1 \pm 0.6$ & $4.3 \pm 0.6$ & $4.2 \pm 0.4$ & $4.4 \pm 0.4$ & $0.171 / 0.3$ \\
\hline Creatine (mg/dL) & $1.3 \pm 1.4$ & $1.5 \pm 1.5$ & $0.9 \pm 0.5$ & $0.8 \pm 0.2$ & $0.04 / 0.002$ \\
\hline Prothrombin time (s) & $19.1 \pm 9.6$ & $17.2 \pm 7.5$ & $13.8 \pm 2.1$ & $13.1 \pm 1.5$ & $0.001 / 0.001$ \\
\hline $\mathrm{CRP}(\mathrm{mg} / \mathrm{dl})$ & $132.1 \pm 92.4$ & $40.4 \pm 31$ & $17.9 \pm 28.3$ & $6.7 \pm 11.5$ & $0.001 / 0.001$ \\
\hline Troponin-I (ng/dl) & $160.5 \pm 460.3$ & $380.2 \pm 1889.7$ & $5.4 \pm 7.6$ & $1.8 \pm 1.7$ & $0.001 / 0.001$ \\
\hline $\mathrm{PaO}_{2} / \mathrm{FiO}_{2}$ & $228.5 \pm 58.8$ & $296.8 \pm 44.8$ & $337.8 \pm 29.5$ & $341.3 \pm 41.1$ & $0.001 / 0.001$ \\
\hline D-Dimer (ng/mL) & $2113.2 \pm 2622.2$ & $1169.8 \pm 1310.8$ & $534.9 \pm 243.8$ & $331.3 \pm 135.2$ & $0.001 / 0.001$ \\
\hline Ferritin $(\mathrm{ng} / \mathrm{mL})$ & $742.4 \pm 1204.9$ & $401.6 \pm 347.3$ & $359.7 \pm 143.1$ & $180.6 \pm 36.7$ & $0.02 / 0.01$ \\
\hline
\end{tabular}

$A R D S$ acute respiratory distress syndrome, $W B C$ white blood cells, $N L R$ neutrophil/lymphocyte ratio, $A S T$ aspartate aminotransferase, $A L T$ alanine aminotransferase, $L D H$ lactate dehydrogenase, $G G T$ gamma glutamyl transferase, $A L P$ alkaline phosphatase, $C O H b$ Carboxyhemoglobin, $p$ comparison of parameters at time of admission and day 5 of treatment between groups

Table 4 Comparison of IL-6 and SP-D levels at admission between COVID-19 patients with and without MAS and ARDS and the control group

\begin{tabular}{|c|c|c|c|c|c|c|}
\hline & \multicolumn{2}{|l|}{ MAS } & \multicolumn{2}{|l|}{ ARDS } & \multirow{2}{*}{$\begin{array}{l}\text { Control } \\
(n=20)(\text { mean } \pm \mathrm{SD})\end{array}$} & \multirow[t]{2}{*}{$p^{*}$} \\
\hline & $\begin{array}{l}+ \\
(n=20)(\text { mean } \pm S D)\end{array}$ & 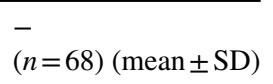 & $\begin{array}{l}+ \\
(n=35)(\text { mean } \pm \mathrm{SD})\end{array}$ & $\begin{array}{l}\overline{-} \\
(n=53)(\text { mean } \pm \mathrm{SD})\end{array}$ & & \\
\hline IL-6 (pg/mL) & $114.5 \pm 60.5^{*}$ & $36.2 \pm 30.4^{*}$ & $91.6 \pm 63.4^{*}$ & $39.4 \pm 30.7 *$ & $25.6 \pm 22.4$ & 0.001 \\
\hline SP-D (ng/mL) & $80.9 \pm 45.5^{*}$ & $53.7 \pm 42.2^{*}$ & $82.3 \pm 45.4^{*}$ & $46.5 \pm 39.2 *$ & $21.1 \pm 18.6$ & 0.001 \\
\hline
\end{tabular}

$p^{*}$ comparison of IL-6 and SP-D levels of patients at hospital admission with control group

Table 5 Comparison of IL- 6 and SP-D levels on day 5 between COVID-19 patients with and without MAS and ARDS and the control group

\begin{tabular}{|c|c|c|c|c|c|c|}
\hline & \multicolumn{2}{|l|}{ MAS } & \multicolumn{2}{|l|}{ ARDS } & \multirow{2}{*}{$\begin{array}{l}\text { Control } \\
(n=20)(\text { mean } \pm \mathrm{SD})\end{array}$} & \multirow[t]{2}{*}{$p^{*}$} \\
\hline & $\begin{array}{l}+ \\
(n=20)(\text { mean } \pm S D)\end{array}$ & $\begin{array}{l}- \\
(n=68)(\operatorname{mean} \pm \mathrm{SD})\end{array}$ & $\begin{array}{l}+ \\
(n=35)(\text { mean } \pm \mathrm{SD})\end{array}$ & $\begin{array}{l}\overline{-} \\
(n=53)(\text { mean } \pm \mathrm{SD})\end{array}$ & & \\
\hline IL-6 (pg/mL) & $46.2 \pm 43.6^{*}$ & $22.4 \pm 20.8$ & $40.1 \pm 34.5^{*}$ & $22.1 \pm 18.6$ & $25.6 \pm 22.4$ & 0.001 \\
\hline SP-D (ng/mL) & $50.4 \pm 18.3^{*}$ & $35.6 \pm 8.4 *$ & $46.4 \pm 33.2^{*}$ & $22.4 \pm 18.9$ & $21.1 \pm 18.6$ & 0.001 \\
\hline
\end{tabular}

$p^{*}$ comparison of IL-6 and SP-D levels of patients at day 5 of treatment with control group

of influenza A and HIV viruses [18, 19]. Studies related to SARS-CoV demonstrated a strong relationship between mutations in the MBL gene and poor prognosis and clinical course $[6,20]$. In studies evaluating the relationship between SP-D level and respiratory and non-respiratory diseases, higher levels were observed with chronic airway diseases and smoking. In addition, significantly higher levels were found in atherosclerosis, which is important in the etiology of diabetes mellitus and coronary artery disease [21, 22]. 
In our study of SARS-CoV-2 (COVID-19) patients, we observed that prothrombin time, CRP, troponin-I, IL-6, and D-dimer levels, all markers previously associated with clinical course and prognosis, were high early in the disease and decreased during follow-up. In addition, elevated liver enzymes were observed during patient follow-up. Although studies suggest that this may be related to the direct effect of the virus on the liver, it may also have been a result of metabolism of favipiravir used in antiviral therapy in the liver [23, 24].

Studies on SARS patients showed that their SP-D levels were higher compared to a healthy control group and patients with community-acquired pneumonia caused by Streptococcus pneumonia [17]. Consistent with the results of previous research, we found that SP-D level was higher in patients with COVID-19 compared to the control group and decreased with treatment. Moreover, SP-D levels were even higher in patients who developed MAS or ARDS compared to those who did not, both at the time of admission and on day 5 of treatment despite the decrease. In light of these data, the increase in SP-D in correlation to the clinical severity of the disease may be attributed to its protective effect, as SP-D is emphasized to be primarily anti-inflammatory.

As with SP-D, we also observed that IL-6 levels at admission and day 5 were relatively higher in patients who developed MAS or ARDS compared to the patients who did not. IL-6 has been identified as a parameter that can be used in the diagnosis and follow-up of cytokine storm syndrome, and studies have shown that the IL-6 antagonist tocilizumab may have an important place in the cytokine storm in particular. Our current data support these previous studies, as we administered $400 \mathrm{mg}$ or $800 \mathrm{mg}$ tocilizumab to our patients who developed MAS during clinical followup. All of the patients in our study who developed MAS also exhibited ARDS. In MAS patients treated with tocilizumab, SP-D level decreased by $50.1 \%$ and IL-6 level decreased by $59.6 \%$ compared to initial levels, while these reductions were $39.2 \%$ for SP-D and $42.3 \%$ for IL-6 in patients with ARDS only. This suggests that the use of tocilizumab in addition to existing antiviral therapy may be beneficial in MAS patients. Our evaluation of the relationship between the patients' comorbidities and the examined parameters showed that diabetes mellitus and being an active smoker or ex-smoker had a greater effect on IL-6 level than SP-D. This may explain our findings of a weak correlation between these two parameters in the correlation analysis. The significantly higher SP-D and IL-6 levels at admission in the 7 nonsurviving patients compared to the survivors could be evaluated as evidence that SP-D and IL-6 are parameters that may be used to guide early treatment approach.

The main limitation observed in our study was the difference in IL-6 level in relation to comorbid diseases and smoking, which limited its association with SP-D level. However, the higher frequency of ARDS and MAS in active or former smokers with comorbid diseases makes it difficult to establish populations with homogeneous distribution. Nevertheless, the fact that both parameters were higher in patients with severe COVID-19 and both regressed during follow-up suggests that the findings can be generalized.

In conclusion, initially high IL-6 and SP-D levels in COVID-19 patients may be guiding parameters for the early planning of close monitoring and treatment in terms of the development of ARDS, MAS, and mortality. Future studies should investigate the potential of SP-D as a pneumoprotein that can be used as a marker for treatment planning for COVID-19 patients.

\section{Compliance with Ethical Standards}

Conflict of interest The authors received no financial support for the research and/or authorship of this article. The authors declare that they have no conflict of interest to the publication of this article.

Ethical Approval All procedures performed in studies involving human participants were in accordance with the ethical standards of the institutional and/or national research committee and with the 1964 Helsinki declaration and its later amendments or comparable ethical standards.

Informed Consent Informed consent was obtained from all individual participants included in the study.

\section{References}

1. Chen N, Zhou M, Dong X, Qu J, Gong F, Han Y, Qiu Y, Wang J, Liu Y, Wei Y (2020) Epidemiological and clinical characteristics of 99 cases of 2019 novel coronavirus pneumonia in Wuhan, China: a descriptive study. Lancet 395(10223):507-513

2. Mehta P, McAuley DF, Brown M, Sanchez E, Tattersall RS, Manson JJ, Collaboration HAS (2020) COVID-19: consider cytokine storm syndromes and immunosuppression. Lancet 395(10229): 1033

3. Rodriguez-Morales AJ, Cardona-Ospina JA, Gutiérrez-Ocampo E, Villamizar-Peña R, Holguin-Rivera Y, Escalera-Antezana JP, Alvarado-Arnez LE, Bonilla-Aldana DK, Franco-Paredes C, Henao-Martinez AF (2020) Clinical, laboratory and imaging features of COVID-19: a systematic review and meta-analysis. Travel Med Infect Dis 34:101623

4. McGonagle D, Sharif K, O'Regan A, Bridgewood C (2020) Interleukin-6 use in COVID-19 pneumonia related macrophage activation syndrome. Autoimmun Rev 19(6):102537

5. Dahmer MK, Flori H, Sapru A, Kohne J, Weeks HM, Curley MA, Matthay MA, Quasney MW, BALI, Investigators RS, Investigators S, (2020) Surfactant protein D is associated with severe pediatric acute respiratory distress syndrome, prolonged ventilation, and death in children with acute respiratory failure. Chest 158(3):1027-1035

6. Park J, Pabon M, Choi AM, Siempos II, Fredenburgh LE, Baron RM, Jeon K, Chung CR, Yang JH, Park C-M (2017) Plasma surfactant protein-D as a diagnostic biomarker for acute respiratory distress syndrome: validation in US and Korean cohorts. BMC Pulm Med 17(1):204 
7. Gorbalenya AE, Baker SC, Baric R, Groot RJd, Drosten C, Gulyaeva AA, Haagmans BL, Lauber C, Leontovich AM, Neuman BW (2020) Severe acute respiratory syndrome-related coronavirus: the species and its viruses-a statement of the coronavirus study group. BioRxiv. https://doi.org/10.1101/2020.02.07.937862

8. Tan L, Wang Q, Zhang D, Ding J, Huang Q, Tang Y-Q, Wang Q, Miao H (2020) Lymphopenia predicts disease severity of COVID19: a descriptive and predictive study. Signal Transduct Target Ther 5(1):1-3

9. Henderson LA, Canna SW, Schulert GS, Volpi S, Lee PY, Kernan KF, Caricchio R, Mahmud S, Hazen MM, Halyabar O (2020) On the alert for cytokine storm: Immunopathology in COVID-19. Arthritis Rheumatol 72(7):1059-1063

10. Qin C, Zhou L, Hu Z, Zhang S, Yang S, Tao Y, Xie C, Ma K, Shang K, Wang W (2020) Dysregulation of immune response in patients with COVID-19 in Wuhan. China. Clin Infect Dis 71(15):762-768

11. Ackermann M, Verleden SE, Kuehnel M, Haverich A, Welte T, Laenger F, Vanstapel A, Werlein C, Stark H, Tzankov A (2020) Pulmonary vascular endothelialitis, thrombosis, and angiogenesis in Covid-19. N Engl J Med 383(2):120-128

12. Guo F, Han X, Guo Y, Zhang D, Tang F, Zhao L, Ji L, Liu W (2017) Correlation study between interleukin-6 levels and coronary reflow. Eur Rev Med Pharmacol Sci 21(8):1837-1842

13. Pradhan AD, Manson JE, Rifai N, Buring JE, Ridker PM (2001) C-reactive protein, interleukin 6 , and risk of developing type 2 diabetes mellitus. JAMA 286(3):327-334

14. Mokeem SA, Alasqah MN, Michelogiannakis D, Al-Kheraif AA, Romanos GE, Javed F (2018) Clinical and radiographic periodontal status and whole salivary cotinine, IL- $1 \beta$ and IL- 6 levels in cigarette-and waterpipe-smokers and E-cig users. Environ Toxicol Pharmacol 61:38-43

15. Gorska K, Nejman-Gryz P, Paplinska-Goryca M, Korczynski P, Prochorec-Sobieszek M, Krenke R (2018) Comparative study of IL-33 and IL-6 levels in different respiratory samples in mild-tomoderate asthma and COPD. COPD 15(1):36-45

16. Sud S, Friedrich JO, Taccone P, Polli F, Adhikari NK, Latini R, Pesenti A, Guérin C, Mancebo J, Curley MA (2010) Prone ventilation reduces mortality in patients with acute respiratory failure and severe hypoxemia: systematic review and meta-analysis. Intensive Care Med 36(4):585-599

17. Wu Y, Liu Z, Wei R, Pan S, Mao N, Chen B, Han J, Zhang F, Holmskov U, Xia Z (2009) Elevated plasma surfactant protein d (sp-d) levels and a direct correlation with anti-severe acute respiratory syndrome coronavirus-specific IgG antibody in SARS patients. Scand J Immunol 69(6):508-515

18. Hartshorn KL, Crouch EC, White MR, Eggleton P, Tauber AI, Chang D, Sastry K (1994) Evidence for a protective role of pulmonary surfactant protein D (SP-D) against influenza A viruses. J Clin Investig 94(1):311-319

19. Madsen J, Gaiha GD, Palaniyar N, Dong T, Mitchell DA, Clark HW (2013) Surfactant Protein D modulates HIV infection of both T-cells and dendritic cells. PLoS ONE 8(3):e59047

20. Determann RM, Royakkers AA, Haitsma JJ, Zhang H, Slutsky AS, Ranieri VM, Schultz MJ (2010) Plasma levels of surfactant protein D and KL-6 for evaluation of lung injury in critically ill mechanically ventilated patients. BMC Pulm Med 10(1):6

21. Moré JM, Voelker DR, Silveira LJ, Edwards MG, Chan ED, Bowler RP (2010) Smoking reduces surfactant protein D and phospholipids in patients with and without chronic obstructive pulmonary disease. BMC Pulm Med 10(1):1-8

22. Sorensen GL (2018) Surfactant protein D in respiratory and nonrespiratory diseases. Front Med 5:18

23. Cai Q, Huang D, Yu H, Zhu Z, Xia Z, Su Y, Li Z, Zhou G, Gou J, Qu J (2020) COVID-19: abnormal liver function tests. J Hepatol 73(3):566-574

24. Du YX, Chen XP (2020) Favipiravir: pharmacokinetics and concerns about clinical trials for 2019-nCoV infection. Clin Pharmacol Ther 108:242-247

Publisher's Note Springer Nature remains neutral with regard to jurisdictional claims in published maps and institutional affiliations. 